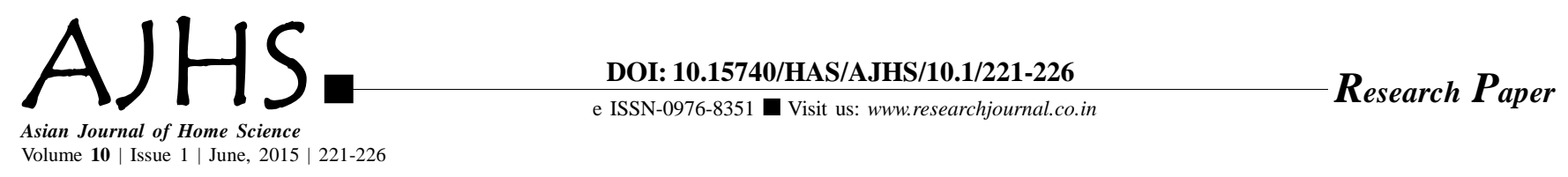

\title{
Classroom interior of high schools in Dharwad
}

\author{
J. MEENAKSHI AND P.R. SUMANGALA
}

Received: 02.05.2015; Revised: 25.05.2015; Accepted: 30.05 .2015

See end of the paper for authors' affiliations J. MEENAKSHI

Department of Family Resource Management, College of Rural Home Science, University of Agricultural Sciences, DHARWAD (KARNATAKA) INDIA

Email : meenasweety.meenakshi @gmail.com
ABSTRACT : School children workplace design and dimensions play a major role in influencing their learning performance. A total sample of six classrooms of high schools was selected purposively for the study. The existing physical interiors were recorded and compared with the BIS recommendation. The results revealed that classroom size, window size, illumination level on students desktop were found to be less than the recommended BIS standards. Also furniture dimensions such as bench height and desk height were found to be higher than the standard. It can be concluded that there is a need to redesign the interiors of the classroom for improved comfort of the users.

KEY WORDS: Classroom interior, High school, Classroom furniture, Illumination

- HOW TO CITE THIS PAPER : Meenakshi, J. and Sumangala, P.R. (2015). Classroom interior of high schools in Dharwad. Asian J. Home Sci., 10 (1) : 221-226. 